Case Report

\title{
Visualization of Soft Tissue Venous Malformations of Head and Neck with 4D Flow Magnetic Resonance Imaging
}

\author{
Ji Ye Lee, MD', Dae Chul Suh, MD²
}

Evaluation of hemodynamics in venous malformation (VM) in the head and neck area is done by direct puncture venography before alcohol sclerotherapy, but it is difficult due to a variable degree of filling in from the artery and filling out into the draining vein. We present our preliminary experience of 4D MRI to evaluate VM hemodynamics. Four patients with venous malformation in the maxillofacial area underwent both 4D MRI and direct puncture venography before alcohol sclerotherapy. To find out appropriate velocity encoding (VENC) for VM, we applied 5-50 cm/sec VENC. Significant high-flow foci demonstrated by phase changes in magnitude images were compared with lesion types shown on a direct puncture venogram. Detection of flow in VM was possible in magnitude images or phase-difference images when VENC was set to less than $30 \mathrm{~cm} / \mathrm{sec}$. Appropriate VENC for VM was regarded as less than 5 $\mathrm{cm} / \mathrm{sec}$. High-flow areas in the dilated venous sac demonstrated focal spots or linear band-like areas on phase changes of 4D MRI. Appropriate VENC application was mandatory to detect flow in VM. Flow information on 4D MRI provided flow information in VM which was not detected on a direct puncture venogram in the compartmentalized lesion and thus can make alcohol sclerotherapy safer.

Key Words : Venous malformation; 4D MRI; Sclerotherapy; Direct puncture venogram

Venous malformations (VMs) are part of a spectrum of vascular malformations commonly found in adults

\footnotetext{
'Department of Radiology, Soonchunhyang University Bucheon Hospital, Bucheon, Korea

${ }^{2}$ Department of Radiology and Research Institute of Radiology, University of Ulsan College of Medicine, Asan Medical Center, Seoul, Korea

Received May 24, 2017; Revised July 18, 2017; Accepted July 20, 2017.

Correspondence to: Dae Chul Suh, MD, PhD, Department of Radiology and Research Institute of Radiology, University of Ulsan College of Medicine, Asan Medical Center, 86 Asanbyeongwon-gil, Songpa-gu, Seoul 05505, Korea.

Tel. 82.2.3010.4366 Fax. 82.2.3010.0090

E-mail: dcsuh@amc.seoul.kr

This is an Open Access article distributed under the terms of the Creative Commons Attribution Non-Commercial License (http://creativecommons.org/licenses/by-nc/3.0) which permits unrestricted non-commercial use, distribution, and reproduction in any medium, provided the original work is properly cited.
}

and children. A venous malformation is defined as a simple malformation with slow flow and an abnormal venous network [1]. Forty percent of cases have been found in the head and neck region, and VM has been known as one of the most difficult disease entities diagnostically and therapeutically in daily practice [2]. VMs are classified into high-flow and low-flow [3]. The latter category accounts for more than $90 \%$ of vascular lesions outside the central nervous system. The differential based on flow dynamics is vital to planning surgical or imaged-guided treatment procedures.

Percutaneous alcohol sclerotherapy has been reported to be effective in the primary treatment of venous malformations of the head and neck region [4-7]. However, it is associated with clinically-important potential complications that have been usually classi- 
fied as either local or systemic. Systemic introduction of alcohol can be dangerous, regardless of dose used, for VM with a rapid outflow of a sclerosing agent, such as absolute alcohol into the draining vein [8]. Thus, it is important to know the hemodynamics of VM to achieve safe and effective alcohol sclerotherapy [9].

Quantitative assessment of hemodynamics may have important clinical applications, including a venous drainage pattern $[3,8,10]$. Although Doppler ultrasonography (US) can be used, the resulting flow parameters are subject to limited reproducibility owing to a limited spatial window and a variable probe orientation. Conversely, phase contrast magnetic resonance imaging allows reliable flow measurement with excellent anatomic localization [11]. Fourdimensional flow MRI is shown to be valid, noninvasive, permitting of quantitative and qualitative analyses of blood flow, and of great clinical potential, since it gives morphologic and anatomical information. The aim of this case report is to demonstrate the flow and velocity patterns in maxillofacial venous malformation with 4D flow MRI.

\section{CASE REPORT}

\section{Patient selection}

This retrospective study included 4 consecutive patients (median 26 years, age range $7-45$ years, 4 male patients) who had undergone 4D flow magnetic resonance imaging at a single tertiary referral center (Asan Medical Center, Seoul, South Korea) for presumed vascular malformations in the head and neck region. The patients were presumed to have venous malformations or hemangiomas based on their clinical presentations. During the procedure, direct puncture of the lesion with contrast injection was done for confirmation of the diagnosis and for identification of anomalous vascular chambers.

\section{MR acquisition for 4D MRI}

MR imaging studies were performed with a 3T MR imaging whole body scanner (Skyra, Siemens Medical Solutions, Germany) by using a 64 channel neurovascular coil for all patients. Data were acquired in an axial 3D volume covering the VM lesion. The following parameters for pulse sequence $4 \mathrm{D}$ flow were constant within all examinations: TR 6.8-7.0 ms, TE 4.0-4.4 ms, 3D slab, $8 \mathrm{~cm}$ coverage, and acquisition time 10-20 mins. Flow-encoding gradients were applied in the feet-head direction corresponding to velocity encoding $(\mathrm{VENC})=50,30 \mathrm{~cm} / \mathrm{s}$ in patient 1 ,
2, 3. Lower VENC $(5,10 \mathrm{~cm} / \mathrm{s})$ was applied in patient 4 for better visualization of phase changes because preceding cases (patient 1,2) failed to demonstrate significant high-flow areas. An FOV of $220 \times 165-183$ $\mathrm{mm}^{3}$ was sampled isotropically with $1.0 \mathrm{~mm}$ resolution. Vessels were segmented based on the complex signal difference between velocity encoding segments.

\section{Data analysis}

All 4D flow data underwent post-processing to correct for Maxwell terms, eddy currents, and velocity aliasing, noise masking with the use of in-house software. Significant high-flow foci were defined as dot-like or band-like high-signal or low-signal intensity within vascular malformation on phase images of $4 \mathrm{D}$ flow MRI. Usefulness for subsequent alcohol sclerotherapy was evaluated. The high-flow component was evaluated for cross-sectional phase changes within the venous lesion.

\section{Direct puncture venography}

Direct needle puncture of the malformation was performed with a 20- or 21-gauge needle by manual palpation. Ultrasound was used in guiding the needle, especially if the malformation is located deep in the soft tissues. The needle was connected to a syringe through a length of extension tubing and is progressively withdrawn while applying slight suction. Once blood return is observed, a small amount of lowosmolality iodinated contrast material is injected to obtain a venogram. Basic phlebographic patterns within VMs were categorized into three patterns [12]. Cavitary pattern lesions are thought to be the most common and demonstrate late venous drainage without evidence of abnormal veins. Spongy pattern VMs consist of multiple "honeycomb" cavities with late venous drainage. Dysmorphic pattern lesions when injected on phlebography rapidly fill dysmorphic veins. Flow characteristics and extent of vascular malformation were evaluated according to the Dubois and Puig classification $[1,13]$. Type I VMs demonstrate a wellcircumscribed or isolated lesion without visible draining veins. Type II VMs have the body of the lesion drain into normal veins and venous system. Type III lesions drain the malformation by ectatic or dysplastic veins. Type IV VMs are comprised entirely of venous ectasia or dysplasia.

\section{RESULTS}

The data of our 4 patients are summarized in Table 1. 
Three patients had VM in superficial area of the face, and one patient had VM in the masticator space. On pre-procedural MRI, all patients had phlebolith, venous pouches with or without enhancement, findings consistent with venous malformation. Two patients did not show phase changes in the phase images obtained by VENC $30-50 \mathrm{~cm} / \mathrm{sec}$. Two patients showed a tiny focus (Fig. 1) or a linear band-like area (Fig. 2) of phase changes obtained by $5-30 \mathrm{~cm} / \mathrm{sec}$ within the venous malformation.

Sclerotherapy was performed after direct puncture venogram which showed large saccular or lobulated malformed venous space with low venous drainage. Direct puncture venographic findings were not directly correlated with 4D MRI because minimal amount of contrast agent was injected into the venous sac and short exposure (several frames of DSA) of X-ray was applied. The speed of venous drainage could not be measured because the contrast agent remained in the malformed venous space and slowly drained into the vein in all cases. No rapid wash-out into the vein corresponded to minimal detection of rapid flow in $4 \mathrm{D}$ MRI. Absolute alcohol sclerotherapy was done by manual compression to make malformed venous space collapse and to get the better alcohol contact with the vessel wall of the venous malformation with minimal drainage into the systemic circulation. Alcohol sclerotherapy was done without any significant systemic complication.

\section{DISCUSSION}

Our study revealed that a high-flow component in the maxillofacial VM can be detected by 4D MRI with VENC less than $5 \mathrm{~cm} / \mathrm{sec}$, and thus showed that 4D MRI could be applied to maxillofacial VM to detect

Table 1. Summary of 4 Patients with Maxillofacial Venous Malformation

\begin{tabular}{|c|c|c|c|c|c|c|c|c|c|c|}
\hline \multirow[t]{2}{*}{$\begin{array}{l}\text { Patient } \\
\text { No. }\end{array}$} & \multirow[t]{2}{*}{$\begin{array}{l}\text { Age/ } \\
\text { Sex }\end{array}$} & \multirow[t]{2}{*}{ Location } & \multirow[t]{2}{*}{ Size $(\mathrm{cm})$} & \multicolumn{3}{|c|}{ 4D MRI } & \multicolumn{3}{|c|}{$\begin{array}{l}\text { Classification on } \\
\text { direct puncture } \\
\text { venogram }\end{array}$} & \multirow{2}{*}{$\begin{array}{c}\text { Amount of } \\
\text { absolute alcohol } \\
\text { for } \\
\text { sclerotherapy } \\
\text { (ml) }\end{array}$} \\
\hline & & & & $\begin{array}{c}\text { VENC } \\
(\mathrm{cm} / \mathrm{sec})\end{array}$ & $\begin{array}{l}\text { High flow } \\
\text { area }\end{array}$ & $\begin{array}{c}\text { High flow lesion } \\
\text { configuration }\end{array}$ & $\begin{array}{l}\text { Dubois } \\
\text { (pattern) }\end{array}$ & $\begin{array}{l}\text { Dubois } \\
\text { and Puig }\end{array}$ & $\begin{array}{l}\text { Venous } \\
\text { drainage }\end{array}$ & \\
\hline 1 & $7 / \mathrm{M}$ & Cheek & $4.5 \times 4.3 \times 1.8$ & 30,50 & No & - & Dysmoprhic & Type 1 & Slow to EVJ & 13 \\
\hline 2 & $45 / F$ & Parotid space & $2.7 \times 1.4 \times 5.6$ & 30,50 & No & - & Cavitary & Type 3 & Slow to IVJ & 5 \\
\hline 3 & $17 / \mathrm{M}$ & Masticator space & $5.7 \times 6.4 \times 3.7$ & 30,50 & Yes & Dot-like & Dysmoprhic & Type 2 & Slow to IJV & 10.5 \\
\hline 4 & $34 / \mathrm{M}$ & Cheek & $5.4 \times 1.5 \times 7.5$ & 5,10 & Yes & Band-like & Spongiform & Type 2 & Slow to IVJ & 17 \\
\hline
\end{tabular}

$\mathrm{VENC}=$ velocity encoding, $\mathrm{EVJ}=$ the external jugular vein, IVJ $=$ the internal jugular vein
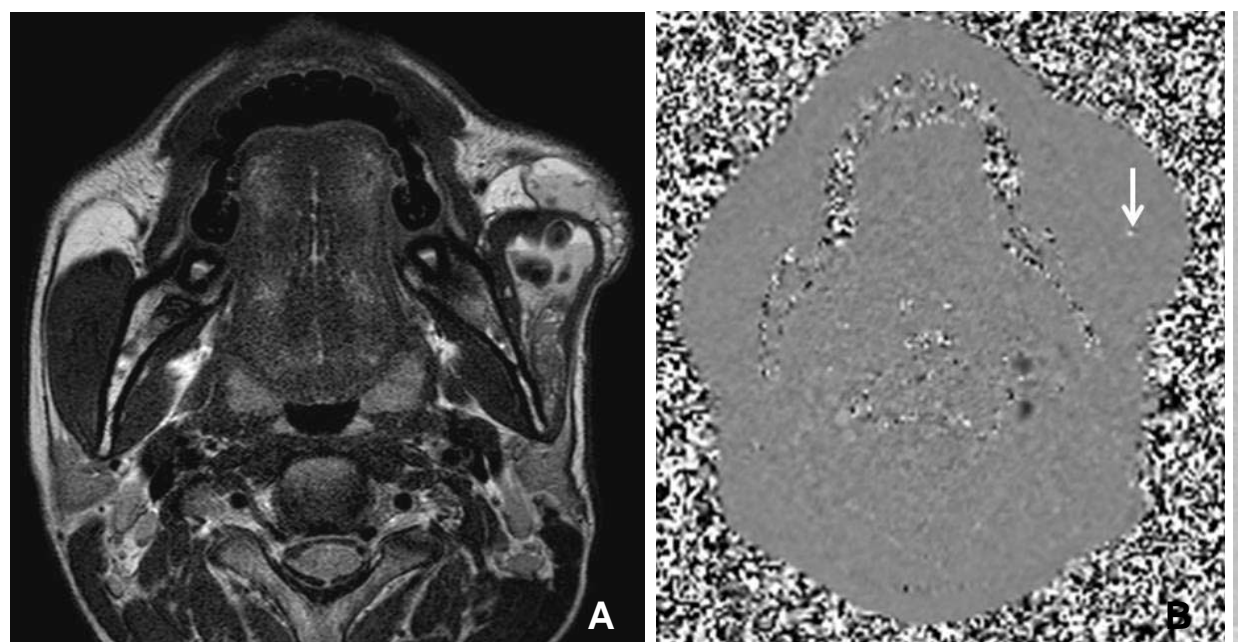

Fig. 1. A 17-year-old male (Patient 3) with venous malformation at left masticator space and cheek. (A) T2WI shows high-signal intense venous malformation at the left masticator space and cheek. (B) Magnitude image of phase-difference images obtained by velocity encoding of $30 \mathrm{~cm} / \mathrm{sec}$ shows a focal phase change in left cheek (arrow). (C) Direct puncture venogram obtained before sclerotherapy shows a dysmorphic lesion pattern and normal-sized venous drainage to the internal jugular vein (type 2). 

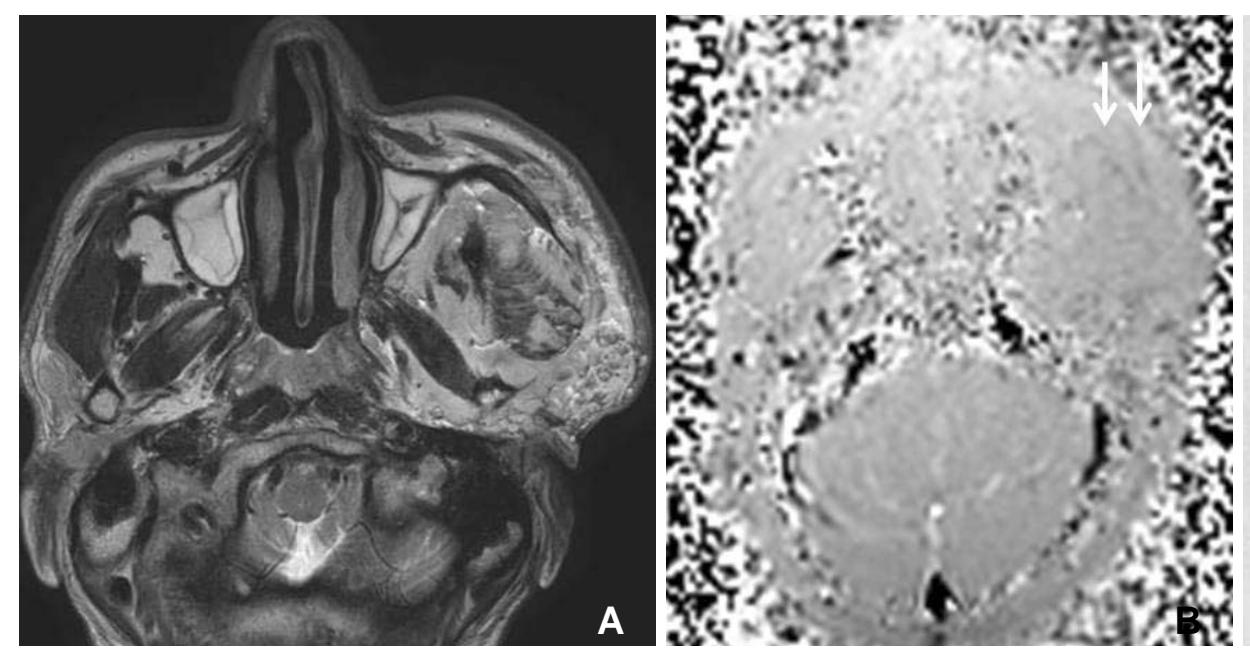

C

Fig. 2. A 35-year-old male (Patient 4) with venous malformation at the left cheek. (A) T2WI and magnitude image shows high signal intense venous malformation at the left cheek (B) The magnitude image of phase-difference images obtained by velocity encoding of 5 $\mathrm{cm} / \mathrm{sec}$ shows a dark signal intense linear shaped incoming flow within the malformed venous sac (arrow). (C) A direct puncture venogram before sclerotherapy shows spongiform lesion pattern and normal-sized venous drainage to the internal jugular vein (type 2).

fast flow components, which could be a source of systemic complications when the injected sclerosing agent enters the systemic circulation. To the best of our knowledge, this is the first study of 4D MRI being applied to maxillofacial VM to detect high-flow components within the lesion. Even though 4D MRI was applicable in head and neck venous malformation, we did not obtain a sufficiently positive finding of high-flow phase change, probably due to the nonexistence of a high-flow component in our study patients or an inappropriate VENC range for the lesion.

4D flow MRI for VM in our study revealed phase changes when the VENC was set less than $5-30 \mathrm{~cm} / \mathrm{s}$. Due to inter-subject variation and the heterogenous complexity of the hemodynamics of venous malformation, the prediction or selection of optimal velocity sensitivity was difficult. The upper limit should be higher than the highest velocity to prevent aliasing, but at the high-upper limit, lowering the technique's sensitivity slows velocities. Since VM is known mainly as a low-flow vascular malformation, low VENC values with less than $5 \mathrm{~cm} / \mathrm{sec}$ would be appropriate to visualize slow venous flow, even though it may cause velocity aliasing at focal areas of fast venous drainage. High-flow spots in the dilated venous sac demonstrated on 4D MRI were revealed as multifocal phase changes and corresponded to flow speed on direct puncture venogram by showing drainage to the internal jugular vein. These findings could aid the treatment decision before the procedure, expecting introduction of a sclerosing agent into the systemic circulation, and subsequently leading to complications.

Vascular malformations can be subdivided into groups depending on the vessel that predominates, i.e. capillary, venous or arterial, and with or without lymphatic anomalies $[1,14]$. The radiological classification used to clarify the dynamics within a lesion should be used to formulate a treatment plan based on the flow characteristics of the vascular lesion [3]. Treatment usually has been sclerotherapy with or without excision for venous malformations and embolization and excision for high-flow lesions [14]. Selective arteriography has been a standard diagnostic method to confirm the presence of high-flow in vascular lesions despite its shortcoming of occasionally causing complications [15]. When a less invasive diagnostic method is used, the necessity for arteriography is reduced except for some critical indications that require preoperative embolization.

Grey-scale and Doppler ultrasound (US) are alternative modalities to diagnose soft-tissue vascular anomalies [16]. However, US has only a limited ability to display the full extent of large lesions and to demonstrate an intra-osseous component $[17,18]$. Some MRI techniques have been used for classification of peripheral vascular lesions [18-20]. Time-of-flight MR angiography can show feeding arteries with highflow; however, this modality has a limitation regarding smaller vessels [19]. A previous study by van Rijswijk et al. [20] has demonstrated that with the use of the dynamic contrast-enhancement gradient-echo technique, venous malformations were distinguished 
from non-venous malformations with high specificity. Another study has demonstrated that time-resolved MR projection angiography was useful for the separation of high- and low-flow vascular malformations [18]. Although direct puncture venography is useful for the diagnosis of VMs and also for confirming lymphatic fluid leaks to differentiate lymphatic malformation from VM, direct puncture venography is used as a part of percutaneous sclerotherapy rather than as a diagnostic procedure due to its relative invasiveness [21]. Blood pool scintigraphy and lymphoscintigraphy can characterize VMs and may be useful for making treatment decisions, even though there is a lack of anatomical details and flow measurement [22]. One advantage of 4D MRI is that it does not require the administration of gadolinium or iodine based contrast material to evaluate hemodynamic characteristics of the vascular malformation.

Our study has several limitations. First, our study did not include a large number of patients. Therefore, venous malformation with high-flow may not be included in our study. Soft compressible venous malformations which are expected to have rapid in- and out-flow can be evaluated with 4D MRI while performing routine facial MRI. Second, there could be selection bias of the enrolled patients with heterogenous features, since the patients underwent various numbers of sclerotherapy treatment sessions. The hemodynamics of VM may change over multiple sclerotherapy treatments sessions. Third, quantitative analysis for velocity to compare with findings of 4D MRI was not obtained in this study. Further study to validate quantitative analysis for the flow velocity within the vascular lesion is required.

In conclusion, application of 4D MRI was feasible for maxillofacial venous malformation. Appropriate set-up for VENC was required to detect flow in VM. Because the flow in venous malformation is slow, VENC less than $5 \mathrm{~cm} / \mathrm{sec}$ is recommended. Flow information on 4D MRI provided better information of VM flow not detected on direct puncture venogram in the compartmentalized lesion and thus can make alcohol sclerotherapy safer.

\section{References}

1. Legiehn GM, Heran MKS. Venous malformations: classification, development, diagnosis, and interventional radiologic management. Radiol Clin North Am 2008;46:545-597

2. Do YS, Yakes WF, Shin SW, Lee BB, Kim DI, Liu WC, et al. Ethanol embolization of arteriovenous malformations: interim results. Radiology 2005;235:674-682
3. Ryu CW, Kim JK, Kim SJ, Lee JH, Kim JH, Ha HI, et al. Head and neck vascular lesions: characterization of the flow pattern by the use of three-phase CT. Korean J Radiol 2009;10:323-332

4. Lee HY, Kim SM, Choi JW, In HS, Cho KJ, Cha EY, et al. The Significance of immunohistochemical staining, including that for glucose transporter protein isoform 1, as related to the clinical and angiographic features of adult soft-tissue hemangioma and arteriovenous malformation in the head and neck. Journal of the Korean Society of Radiology 2009;60:83-91

5. Yakes WF, Luethke JM, Parker SH, Stavros AT, Rak KM, Hopper KD, et al. Ethanol embolization of vascular malformations. Radiographics 1990;10:787-796

6. Berenguer B, Burrows PE, Zurakowski D, Mulliken JB. Sclerotherapy of craniofacial venous malformations: complications and results. Plast Reconstr Surg 1999;104:1-11

7. Mason KP, Michna E, Zurakowski D, Koka BV, Burrows PE. Serum ethanol levels in children and adults after ethanol embolization or sclerotherapy for vascular anomalies. Radiology 2000;217:127-132

8. Baek HJ, Hong JP, Choi JW, Suh DC. Direct percutaneous alcohol sclerotherapy for venous malformations of head and neck region without fluoroscopic guidance: technical consideration and outcome. Neurointervention 2011;6:84-88

9. Moukaddam H, Pollak J, Haims AH. MRI characteristics and classification of peripheral vascular malformations and tumors. Skeletal Radiol 2009;38:535-547

10. Ryu CW, Whang SM, Suh DC, Kim SM, Jang YJ, Kim HJ, et al. Percutaneous direct puncture glue embolization of high-flow craniofacial arteriovenous lesions: a new circular ring compression device with a beveled edge. AJNR Am J Neuroradiol 2007; 28:528-530

11. Hope TA, Zarins CK, Herfkens RJ. Initial experience characterizing a type I endoleak from velocity profiles using time-resolved three-dimensional phase-contrast MRI. J Vasc Surg 2009;49: 1580-1584

12. Dubois J, Soulez G, Oliva VL, Berthiaume MJ, Lapierre C, Therasse E. Soft-tissue venous malformations in adult patients: imaging and therapeutic issues. Radiographics 2001;21:15191531

13. Dubois JM, Sebag GH, De Prost Y, Teillac D, Chretien B, Brunelle FO. Soft-tissue venous malformations in children: percutaneous sclerotherapy with Ethibloc. Radiology 1991;180: 195-198

14. Jackson IT, Carreño R, Potparic Z, Hussain K. Hemangiomas, vascular malformations, and lymphovenous malformations: classification and methods of treatment. Plast Reconstr Surg 1993;91: 1216-1230

15. Burrows PE, Mulliken JB, Fellows KE, Strand RD. Childhood hemangiomas and vascular malformations: angiographic differentiation. AJR Am J Roentgenol 1983;141:483-488

16. Trop I, Dubois J, Guibaud L, Grignon A, Patriquin H, McCuaig C, et al. Soft-tissue venous malformations in pediatric and young adult patients: diagnosis with Doppler US. Radiology 1999;212: 841-845

17. Fordham LA, Chung CJ, Donnelly LF. Imaging of congenital vascular and lymphatic anomalies of the head and neck. Neuroimaging Clin N Am 2000;10:117-136

18. Ziyeh S, Schumacher M, Strecker R, Rössler J, Hochmuth A, Klisch J. Head and neck vascular malformations: time-resolved 


\section{D-MRI of Head and Neck venous Malformations}

MR projection angiography. Neuroradiology 2003;45:681-686

19. Dobson M, Hartley R, Ashleigh R, Watson Y, Hawnaur J. MR angiography and MR imaging of symptomatic vascular malformations. Clinical Radiology 1997;52:595-602

20. van Rijswijk CS, van der Linden E, van der Woude HJ, van Baalen JM, Bloem JL. Value of dynamic contrast-enhanced MR imaging in diagnosing and classifying peripheral vascular malformations. AJR Am J Roentgenol 2002;178:1181-1187
21. Lee BB, Kim DI, Huh S, Kim HH, Choo IW, Byun HS, et al. New experiences with absolute ethanol sclerotherapy in the management of a complex form of congenital venous malformation. $J$ Vasc Surg 2001;33:764-772

22. Kim YH, Choi JY, Kim YW, Kim DI, Do YS, Hwang JH, et al. Characterization of congenital vascular malformation in the extremities using whole body blood pool scintigraphy and lymphscintigraphy. Lymphology 2009;42:77-84 